\title{
Primary melanoma of the male urethra
}

\author{
Hatice Karaman ${ }^{1}$, Yüksel Yeşil ${ }^{2}$
}

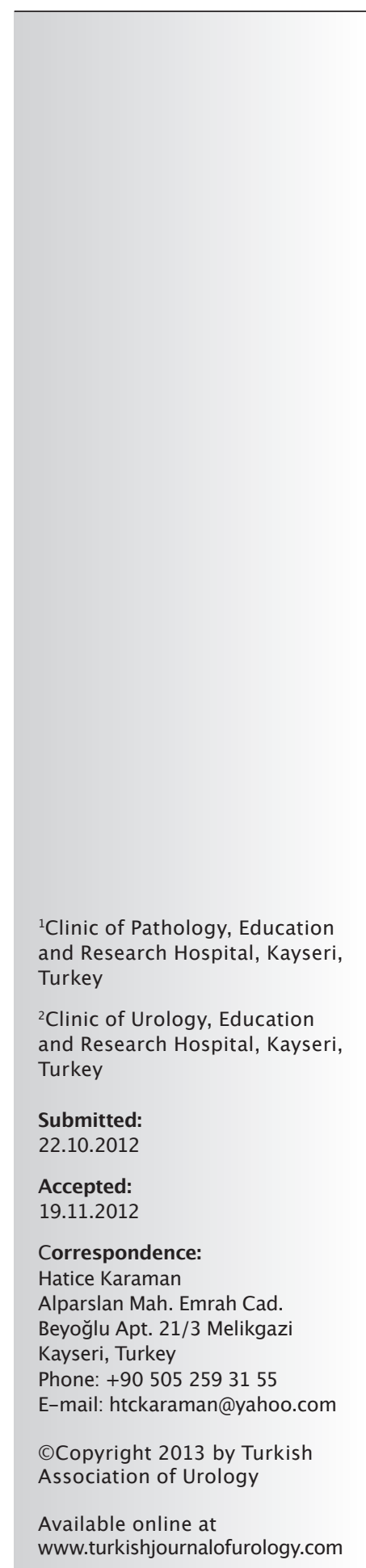

\begin{abstract}
Primary melanomas of the genitourinary tract are rare and have poor prognoses. We report a case of a urethral malignant melanoma of a 63-year-old man. This case was regarded as a primary malignant melanoma of the urethra according to histopathological and immunohistochemical findings. Herein, the case is presented and the relevant literature is reviewed and discussed.
\end{abstract}

Key words: Malignant melanoma; male; urethra.

\section{Introduction}

Primary malignant melanoma of the male urethra is extremely rare with a poor prognosis. Malignant melanoma of the male genito-urinary tract is most frequently localized on urethra, and penis. Early diagnosis, and surgical treatment effect clinical prognosis. Urethral melanomas rarely manifest clinical symptoms, and its delayed detection retards effective treatment. ${ }^{[1]}$ Definitive diagnosis is made based on histopathological findings. In our case, the patient underwent biopsy with the initial diagnosis of urethral caruncle, and histopathology was reported as malignant melanoma.

\section{Case presentation}

A 63-year-old male patient consulted to our urology outpatient clinic with complaints of difficulty in urinating, weak urine flow, blood coming from meatus following sexual intercourse. From his medical history, we learnt that he had these complaints for nearly a year, and discerned a mass protruding from his urethra. His penile, scrotal, and inguinal region examination did not reveal any abnormality except for an erythematous polypoid mass measuring $0.6 \times 0.5 \mathrm{~cm}$ with a thin pedicle protruding from his external meatus. Cystourethroscopy demonstrated an oval mass lesion with a sessile pedicle arising from mucosa of fossa navicularis and protruding from external meatus. Any other abnormality was not detected within the proximal urethra, and bladder. The mass was sent to the pathology with the initial diagnosis of caruncle. Histopathological examination disclosed neoplastic cells with vesicular nuclei on eccentric locations, conspicuous nucleoli, and atypic cells with eosinophilic cytoplasms aligned in niches (Figure 1). During immunohistochemical examination tumor cells stained diffusely with HMB-45, and MART-1 melanin were seen. Thoracal, and abdominopelvic computed tomograms of the patient obtained at a later date did not reveal any sign of metastasis. Dermatological examination performed during postoperative period was unremarkable. His 6-month follow-up period was uneventful.

\section{Discussion}

Non-urothelial neoplasms of urinary tract are rarely seen, and constitute less than $1 \%$ of all malignant melanomas of the genito-urinary tract. ${ }^{[2]}$ Primary malignant melanomas consist nearly $4 \%$ of urothelial tumors. ${ }^{[1-17]}$ Malignant melanomas are most often localized within distal urethra. In men it is most frequently found in fossa navicularis $(55 \%)$, urethral meatus $(5 \%)$, pendulous $(15 \%)$, bulbous $(10 \%)$, and prostatic urethra $(15 \%)$. In some patients it is localized in glans penis. [7,18] Metastatic malignant melanomas are mostly encountered in glans penis which deserve detailed clinical information, and meticulous physical examination. ${ }^{[2]}$

Malignant melanoma of the male urethra was firstly reported by Tyrell in the year $1871 .^{[3]}$ 


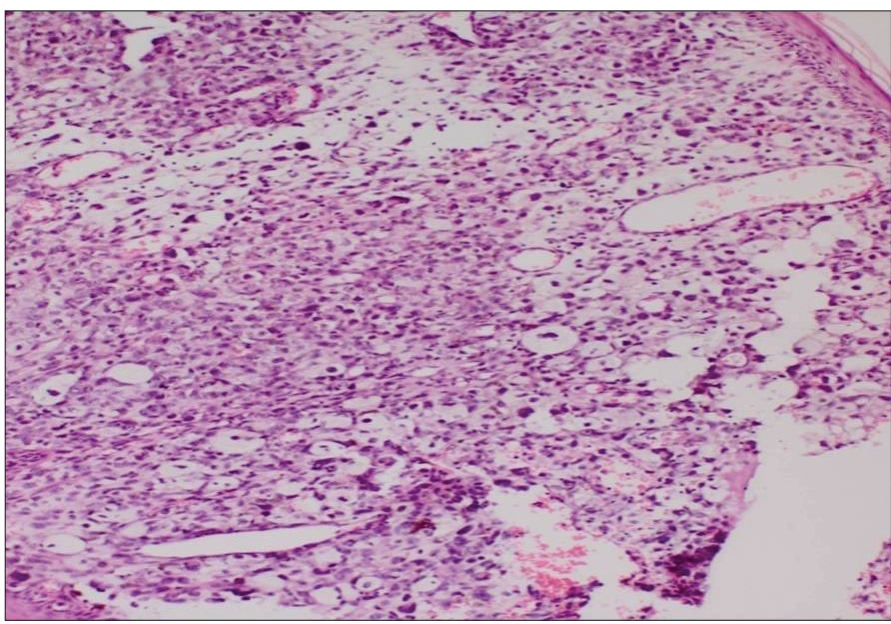

Figure 1. Subepithelial pleomorphic atypical tumor cells (H\&E x20]

Later on, small series of malignant melanoma of the urethra were published in England (1-10). Only two cases were reported from Korea. ${ }^{[12,19]}$

Clinical findings of urothelial melanomas liken to those of other urothelial tumors. Hematuria is the most frequently encountered symptom. In some patients melanuria, and a dark pigmented lesion aid in diagnosis. The patients usually apply to the hospital at an advanced stage, and widespread metastases are seen at the time of diagnosis..$^{[12-18]}$ Since tumors have a polypoid appearance, they are confused with urothelial polyp, urethral caruncle or malignant urothelial neoplasias. ${ }^{[5]}$

Histopathological evaluation reveals a wide spectrum of abnormal findings including diffuse or patchy areas of pleomorphic cells demonstrating pseudoglandular development in niches. [13] Tumor consists of epitheloid or spindle shaped cells with or without melanin pigment. It is very difficult to establish diagnosis in cases of amelanotic melanomas. In the differential diagnosis sarcoma, spindle cell carcinoma, and poorly differentiated urothelial carcinomas should be considered. Diagnosis of urothelial primary melanoma can be made by confirming absence of primary lesions elsewhere. Immunohistochemical markers including S-100, HMB-45, and Melan A aid in differential diagnosis.

Urothelial malignant melanomas have a poor prognosis compared with cutaneous lesions. Many urethral melanomas might already invade into deep anatomical structures, and also inguinal lymph node and also distant metastases can be seen at the time of diagnosis. ${ }^{[14]}$ Since it metastasizes into adjacent organs, regional lymph nodes, and in some cases into distant organs via hematogenous route, it has a very poor prognosis. ${ }^{[15-18]}$

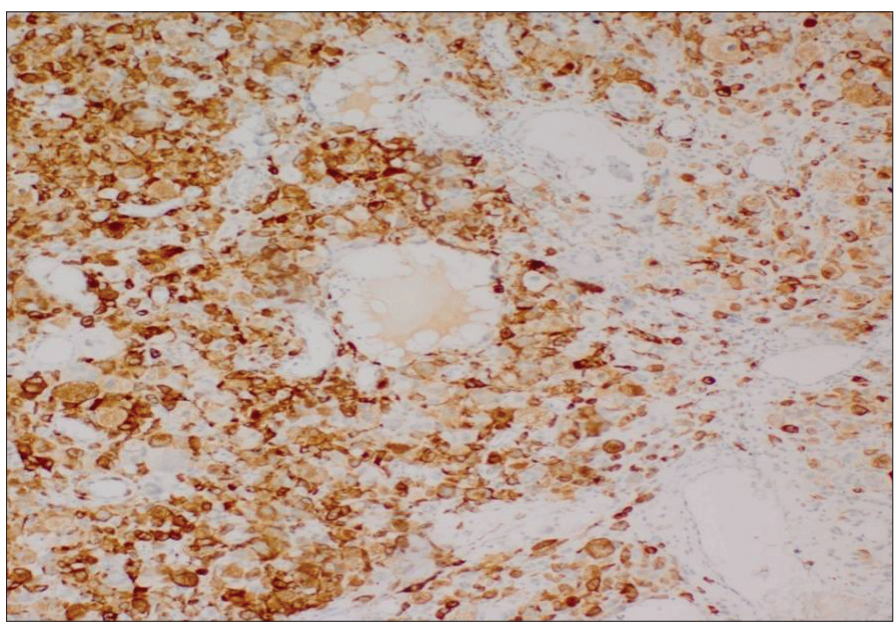

Figure 2. MART-1 Tumor cells positively stained with melanin (H\&E x 100]

Therefore, partial or total penectomy together with inguinal lymph node dissection is the treatment of choice. ${ }^{[2,16]}$

A complete consensus has not been reached for the treatment of cases with primary malignant melanoma of the urethra. Literature reviews have revealed various treatment alternatives recommended by different researchers ranging from subtotal urethrectomy to anterior pelvic exenteration. Besides scarce number of cases have been reported so far. Since malignant melanoma of the urethra metastatize at an early stage of the disease, early diagnosis is essntial, and an extensive surgical excision before development of metastases seems to be the only treatment alternative..$^{[1-18]}$

Rikaniadis et al. ${ }^{[17]}$ recommended local excision as a conservative treatment modality which maintains quality of life of the patient in selected cases of malignant melanoma localized in distal urethra. ${ }^{[18]}$ Lee et al. ${ }^{[19]}$ noted disease-free survival during a 12 months of the follow-up period in a 74-year-old patient diagnosed as primary malignant melanoma of the urethra without lymph node involvement who had undergone partial penectomy, and lymph node dissection.

Lymph node or distant metastasis was not detected in our patient. The patient underwent partial penectomy, and lymph node dissection. Dermatological examination performed during the postoperative period was unremarkable. During 6 months of follow-up period any problem was not encountered.

Peer-review: Externally peer-reviewed.

Author Contributions: Concept - H.K.; Design - H.K.; Supervision H.K.; Funding - H.K.; Materials - H.K.; Data Collection and/or Processing - H.K., Y.Y.; Analysis and/or Interpretation - H.K.; Literature Review - H.K. 
Conflict of Interest: No conflict of interest was declared by the authors.

Financial Disclosure: The authors declared that this study has received no financial support.

\section{References}

1. Katz EE, Suzue K, Wille MA, Krausz T, Rapp DE, Sokoloff MH. Primary malignant melanoma of the urethra. Urology 2005;65:389.

2. Oliva E, Quinn TR, Amin MB, Eble JN, Epstein 31, Srigley JR, et al. Primary malignant melanoma of the urethra: a clinicopathologic analysis of 15 cases. Am J Surg Pathol 2000;24:785-96.

3. Tyrell HJ. Melanotic tumor of the urethra. Proc Pathol Soc Dublin 1871;4:194.

4. Watanabe J, Yamamoto S, Souma T, Hida S, Takasu K. Primary malignant melanoma of the male urethra. Int J Urol 2000;7:351-3.

5. Lopez JI, Angulo JC, Ibanez T. Primary malignant melanoma mimicking urethral caruncle. Case report. Scand J Urol Nephrol 1993;27:125-6.

6. van Geel AN, den Bakker MA, Kirkels W, Horenblas S, Kroon BB, de Wilt JH, et al. Prognosis of primary mucosal penile melanoma: a series of 19 Dutch patients and 47 patients from the literature. Urology 2007;70:143-7.

7. Manivel JC, Fraley EE. Malignant melanoma of the penis and male urethra: 4 case reports and literature review. J Urol 1988;139:813-6.

8. Weiss J, Elder D, Hamilton R. Melanoma of the male urethra: surgical approach and pathological analysis. J Urol 1982;128:382-5.

9. Pow-Sang JM, Klimberg IW, Hackett RL, Wajsman Z. Primary malignant melanoma of the male urethra. J Urol 1988;139:1304-6.

10. DiMarco DS, DiMarco CS, Zincke H, Webb MJ, Keeney GL, Bass $\mathrm{S}$, et al. Outcome of surgical treatment for primary malignant melanoma of the female urethra. J Urol 2004;171:765-7.

11. Calcagno L, Casarico A, Bandelloni R, Gambini C. Primary malignant melanoma of male urethra. Urology 1991;37:366-8.
12. Lee GG, Cheon SH, Hwang HH, Kim YM, Park RJ. Primary malignant melanoma of the male urethra. Korean J Urol 2005;46:764-6.

13. Nakhleh RE, Wick MR, Rocamora A, Swanson PE, Dehner LP. Morphologic diversity in malignant melanomas. Am J Clin Pathol 1990;93:731-40.

10. DiMarco DS, DiMarco CS, Zincke H, Webb MJ, Keeney GL, Bass $\mathrm{S}$, et al. Outcome of surgical treatment for primary malignant melanoma of the female urethra. J Urol 2004;171:765-7.

11. Calcagno L, Casarico A, Bandelloni R, Gambini C. Primary malignant melanoma of male urethra. Urology 1991;37:366-8.

12. Lee GG, Cheon SH, Hwang HH, Kim YM, Park RJ. Primary malignant melanoma of the male urethra. Korean J Urol 2005;46:764-6.

13. Nakhleh RE, Wick MR, Rocamora A, Swanson PE, Dehner LP. Morphologic diversity in malignant melanomas. Am J Clin Pathol 1990;93:731-40.

14. Yoshizawa T, Kawata N, Sato K, Hirakata H, Igarashi T, Ichinose T, et al. Primary malignant melanoma of the female urethra. Urology 2007;70:1222.e13-6.

15. Robutti F, dpBetta PG, Bellingeri M, Bellingeri D. Primary malignant melanoma of the female urethral meatus. Eur Urol 1986;12:62-3.

16. Eryıldırım B, Erbay E, Kuyumcuoğlu U, Tarhan F. Primary malignant melanoma of the female urethra. Turkish Journal of Urology 2004;30:366-8.

17. Rikaniadis N, Konstadoulakis MM, Kymionis GD, Tsibloulis B, Peveretos P, Karakousis CP. Long-term survival of a female patient with primary malignant melanoma of the urethra. Eur J Surg Oncol 1998;24:607-8.

18. Oxley JD, Corbishley C, Down L, Watkin N, Dickerson D, Wong NA. Clinicopathological and molecular study of penile melanoma. J Clin Pathol 2012;65:228-31.

19. Lee SW, Kim EK, Mi Lee W, Man Jo J, Keun Yoo T, Yoon Kang J. Primary Malignant Melanoma of the Male Urethra. The Korean Journal of Pathology 2010;44:662. 